\title{
Behaviour of the Red Howler Monkey (Alouatta seniculus) in the Llanos of Venezuela
}

\author{
F. Braza, F. Alvarez and T. Azcarate \\ Estación Biológica de Doñana, Spain
}

\begin{abstract}
The behaviour of the red howler monkey (Alouatta seniculus) in the Llanos of Venezuela was studied from May 1975 to May 1976. The average size of the social groups was $6.3 \pm 2.1$ individuals. The groups were heterosexual, comprising individuals of all ages, with an average of $40 \%$ adult females, $26 \%$ adult males, $16 \%$ juveniles and $18 \%$ infants. The daily rhythm of activity for the performance of locomotion, feeding, snoozing and sleeping was ascertained for dry and rainy seasons. The density of the population in the whole area of study was $\mathbf{0 . 2 5}$ individuals per hectare of woodland, although a density of as high as 0.54 individuals per hectare was reached in some places. The use of space was established by means of locations, howls, fecal piles and scent-marking. Howlers discriminated very much in their performance of various activities in the vertical strata of trees, their use being apparently controlled mainly by the howlers' quadrupedal locomotion and by the necessity for protection against predators.
\end{abstract}

\section{INTRODUCTION}

Studies on howler monkeys began in the 30 's with Alouatta villosa $(=$ A. palliatta $)$ being the species most extensively investigated. Observations on $A$. seniculus and $A$. caraya began in the 60 's, while $A$.guariba and $A$. belzebul remain little known (BALDWIN, PATTERSON \& TeleKI, 1977). Those aspects of the behaviour which are most concerned with this study, i.e., the group parameters, daily rhythm of activity and vertical use of space, will be reviewed first.

Information related to these subjects has been obtained for $A$. villosa in Panama, Costa Rica and Guatemala, the group size being the largest among all species of howlers (average 10 to 18 individuals). The proportion of adult females is superior to that of adult males in these groups (36-44\% of females, $20-28 \%$ of males). Such howlers do not show any nocturnal activity. Moreover, they spend most of the daytime sleeping $(51-73 \%)$ and the rest of the time eating and moving about, with feeding peaks occurring in the early morning and late evening. The density of animals ranges from 0.5 to 0.8 individuals per hectare, with the exception of the very high density shown in southwestern Panama. The home range size is 4.9 ha in Chiriqui, Panama, measuring $109-183 \mathrm{~m}$ in length in Barro Colorado, Panama (CARPenter, 1934; AltmanN, 1959; Bernstein, 1964; Baldwin \& Baldwin, 1972; MitTermeir, 1973; FreEse, 1975; COelHo et al., 1976).

A. caraya has been studied by Pope (1966) in northern Argentina, where the group size varies from 4 to 14 individuals, with an average of 7 . These groups have an equal proportion of adult males and females. There are no reports in the literature concerning the rhythm of activity and use of space in $A$. caraya.

The species considered in this report (A. seniculus) has been studied in the Llanos of the Venezuelan state of Guárico and in the Upper Amzonas and National Park La Macarena, in Colombia. The monkeys live in very cohesive groups, the average size of which varies be- 
tween five and eight individuals. The populations observed by NeviLle (1972) in the Venezuelan Llanos and woods of Trinidad showed approximately the same proportion of adult males and females, while the groups observed by Izawa (1975) in Colombia very frequently had a single adult male and several females. Their density varies from 0.1 to 1.1 individuals per hectare, and the area of the home range is from 3.2 to 6.6 ha. Red howlers prefer to utilize the continuous strata of woods although at times they go down to the ground (NEVILLE, 1972; IZAWA, 1976; KLEIN \& KLEIN, 1976).

Yearly cycle observations of this species are missing from the above studies, as is detailed information on the activity rhythm, group cohesion, variations in group size, and the composition and use of the forest strata. We therefore attempted to study these topics in $A$. seniculus in the low Llanos of Venezuela, and compared our results with those obtained for other species of Alouatta.

\section{STUDY AREA}

Field observations were carried out in Hato "E1 Frío," a region of about 78,000 ha located between the settlements of Samán and Mantecal, in the Venezuelan State of Apure, with the rivers Guaritico and Apure at its northern limits and the river Caucagua at the south. Most observations were carried out in a selected study area (Fig. 1) covering 30,000 ha of wood and savannah.

The average annual rainfall in San Fernando de Apure (190 km east-northeast of the study area) is $1,424 \mathrm{~mm}$, of which $90 \%$ corresponds to the rainy season (May to October). The average temperature is $27.1^{\circ} \mathrm{C}$, April being the warmest month $\left(29^{\circ} \mathrm{C}\right)$ and June the least warm $\left(25.6^{\circ} \mathrm{C}\right)$. The average relative humidity varies from $62 \%$ in March to $85 \%$ in July. The prevailing winds are from the east and northeast, with an average speed of $7 \mathrm{~km} / \mathrm{hr}$ (OJASTI, 1973).

According to Ramia (1966), the Apurenian savannahs cover $70 \%$ of the area of the state, and this proportion was apparently appropriate to the zone studied. The remaining $30 \%$ is made up of woods of different types, which either follow the course of the rivers forming socalled gallery forests or exist as isolated patches, or islands forests, in the middle of the savannah.

Based on their structure and the regular seasonal rainfall, following RICHARDS (1964), we classify the woods in the study area as semi-deciduous seasonal forests. In them we were able to distinguish two vertical strata: an upper, discontinuous one with individual trees which sometimes exceeded $20 \mathrm{~m}$ in height, and a lower, continuous one with individual trees of 3 to $10 \mathrm{~m}$ in height. In the upper stratum, 20 to $30 \%$ of the trees are generally deciduous, while the lower stratum trees are mainly perennial but include a considerable number of deciduous species. Other features of these forests are the presence of woody lianes and the absence of grasses in the scarce ground vegetation.

\section{POPULATION DENSITY}

The 30,000 ha of the study area included only 1,000 ha of wood, i.e., about $3 \%$ of the total. The counting of howlers during the whole year resulted in a figure of 256 individuals living in these woods, giving a density of 0.25 animals per hectare. These individuals were included in 36 social groups. Parts of the habitat were unfit for use by the howlers. These were occupied 


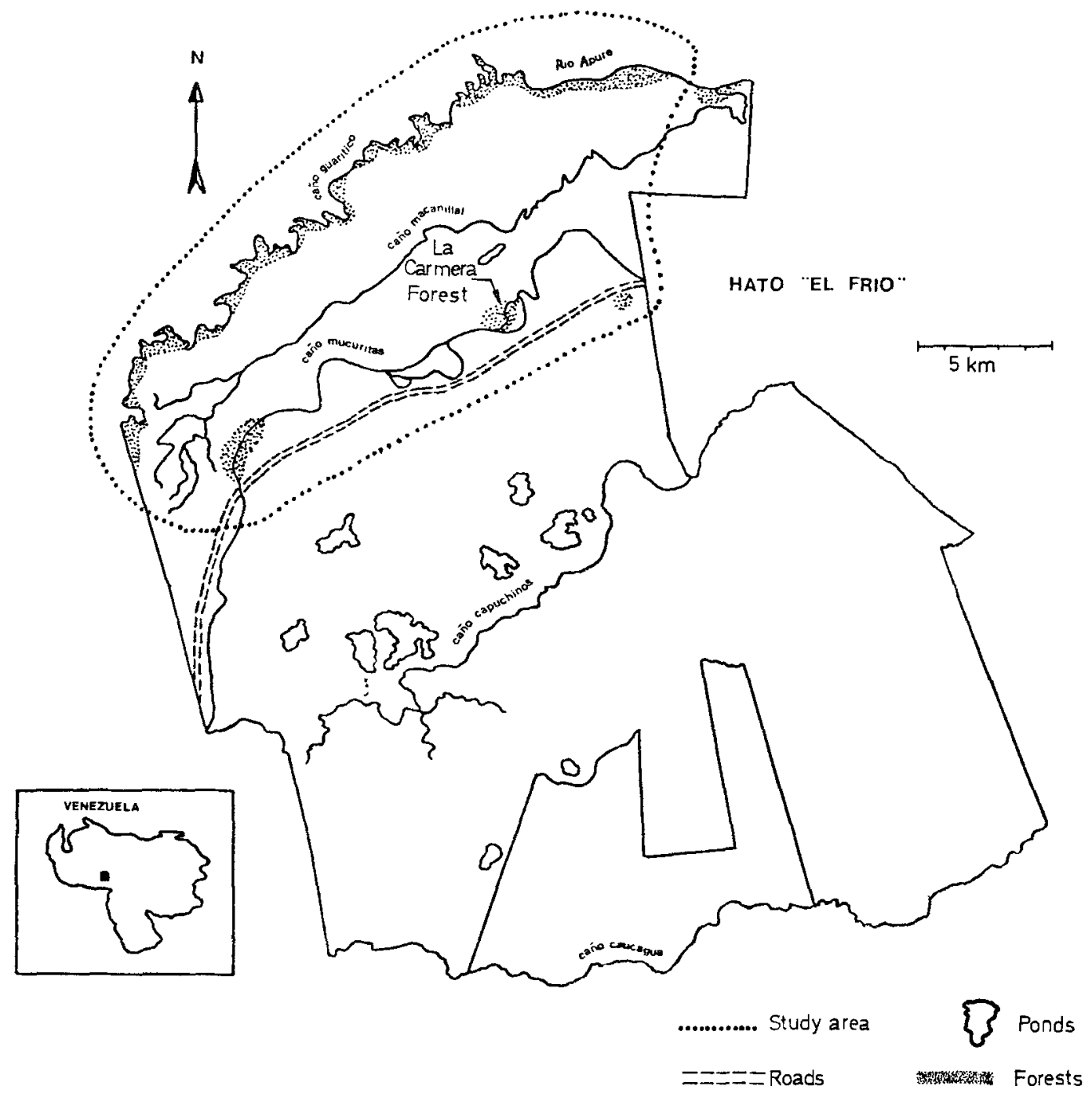

Fig. 1. Study area, showing the principal biotopes.

by immature woods (probably as a result of deforestation), with a single continuous stratum of low trees, or the wood was insufficiently dense, having sometimes only a single line of trees following the course of the rivers.

Within the area of study, the wood named "La Carmera" was the most intensively explored, and the location of each group in this wood was recorded. We were able to show that six groups of howlers with a total population of 38 individuals (density of 0.54 individuals per hectare) lived in the 70 ha of the wood.

\section{GROUP PARAMETERS}

DATA RECORDING

We approached the problem of gregariousness by employing the criteria of group size and 
composition and its degree of cohesion in the population studied. With regard to the first two criteria, the data were collected by covering almost all the study area throughout the year. On these trips we looked for the groups and noted their location, size and composition in terms of age and sex classes (adult male, adult female, juvenile and infant). The external genitalia as well as greater body size and throat thickness, were found to be useful for differentiating males from females. Juveniles and infants were identified mainly from their body size and degree of attachment to the mother.

To analyze the cohesion-dispersion of the members in a group, the number of trees over which the group was spread was noted every 5 min during days when the activity of the group was recorded. The index so obtained therefore gave a measure of the dispersion.

\section{Group Size}

We observed single males, male-male and male-female pairs, a single group of three males and heterosexual groups comprising more than two individuals. The frequencies of each of these associations are shown in Table 1. Clearly, howlers tend to gather themselves into groups of more than two individuals. The group size varied from 3 to 13 members (average 6.3, S.D. $=2.1$ ).

Table 1. Group sizes.

\begin{tabular}{lcccc}
\hline Type of association & $\begin{array}{l}\text { No. of } \\
\text { groups }\end{array}$ & $\begin{array}{l}\text { Range of } \\
\text { variation }\end{array}$ & Mean value & S.D. \\
\hline Associations of more than 2 individuals & 141 & $3-13$ & 6.3 & 2.1 \\
Single male & 9 & & & \\
2 males & 2 & & \\
3 males & 1 & & \\
1 male-1 female & 6 & & \\
Total groups observed & 159 & & \\
\hline
\end{tabular}

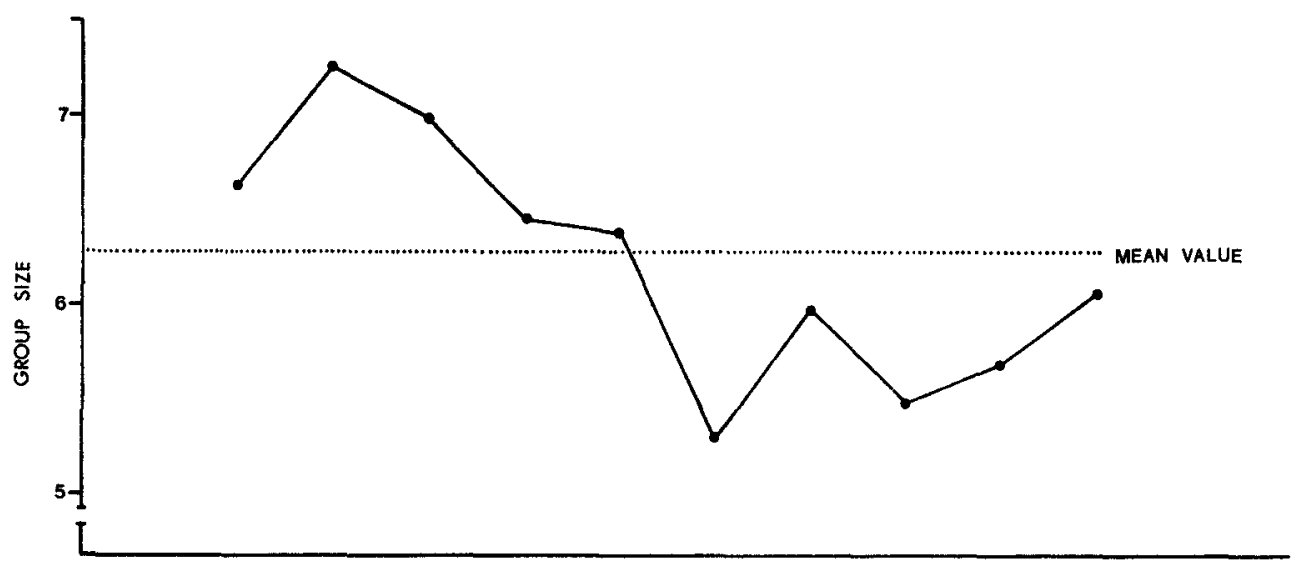

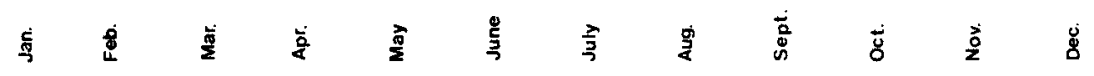

Fig. 2. Mean group size variation within the year of study. 


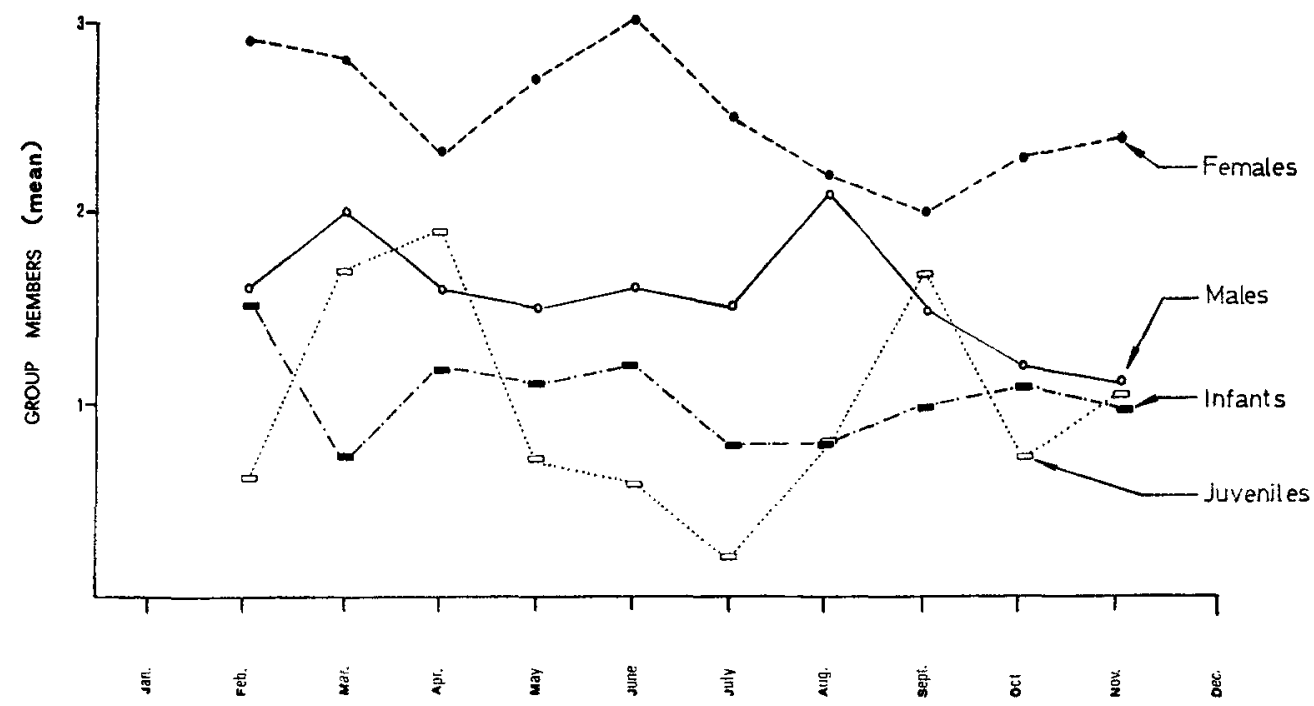

Fig. 3. Variation of group composition within the year of study.

Considering the variation in group size throughout the year, it can be appreciated from Figure 2 that the average value for the first half of the year was significantly higher than the group size for the second half ( $p<0.01$, Student's $t$ test), the time of descent in group size (June-July) coinciding approximately with the beginning of the rainy season. It is interesting to note that the largest-sized groups appeared in March, the driest month, and the smaller groups were found in the rainiest month, July.

\section{Group COMPOSITION}

Not only does the group vary in size throughout the year, but it varies also in composition. The data in Figure 3 show that a larger proportion of females to males and of both of these

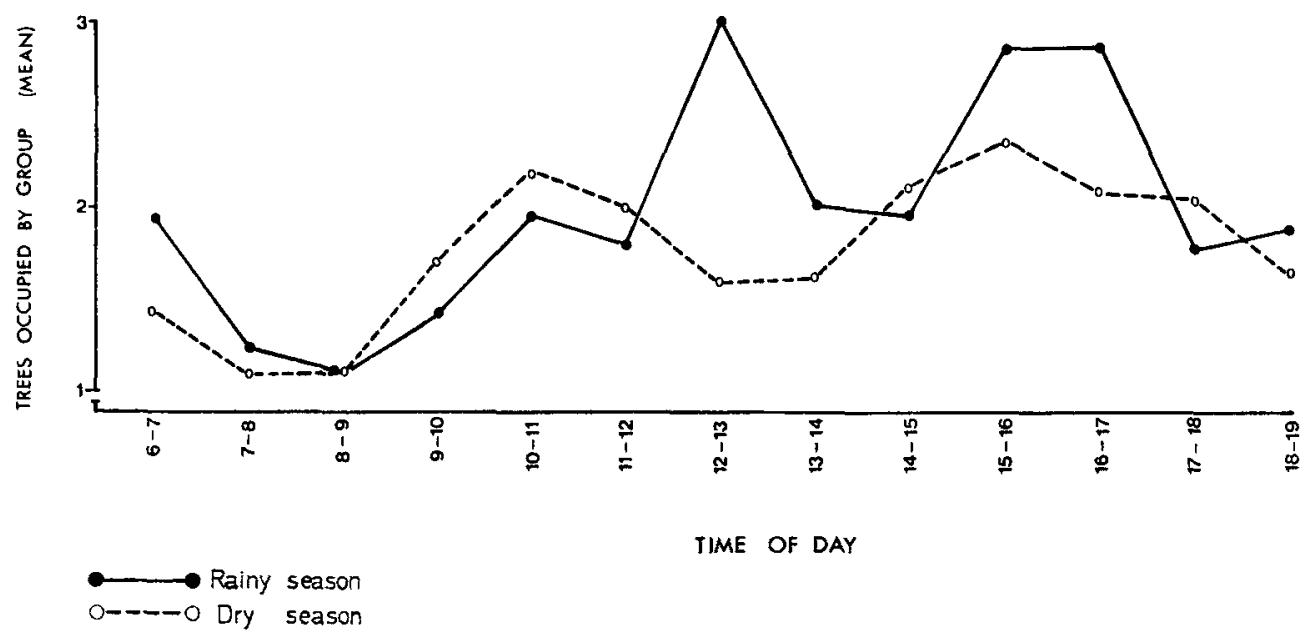

Fig. 4. Mean number of trees occupied by the study group within the day. 
classes to infants is maintained throughout the year (significant in all cases, $p<0.01$, Wilcoxon $U$ test). It can also be seen that although the average numbers of adult males and infants do undergo slight variations, the variations in the case of adult females and juveniles are large, so that when the frequency of the latter decreases, that of the females increases (significant, $r_{s}=0.84, p<0.01$, Spearman test).

The proportions of the different age and sex classes represented in the groups were: $40.2 \%$ adult females, $26.0 \%$ adult males, $16.0 \%$ juveniles and $17.8 \%$ infants.

\section{COHESION-DISPERSION}

Figure 4 shows the average number of trees occupied during the day by the most observed group, representing eight complete days of observation in each season of the year of study. Although the differences between the two distributions are slight, it can be seen from Figure 4 that the maximum values during the rainy season are higher than those for the dry season.

\section{ACTIVITY RHYTHM}

\section{METHODS}

The data on the activity rhythm were based on direct observation of a group of howlers whose behaviour was noted in detail at the end of each period of $5 \mathrm{~min}$. For each of these samples, the following activities were noted: locomotion, feeding, snoozing and sleeping. The last two activities are considered independently here, since the postures adopted are different and the group is more concentrated while sleeping.

For the present purposes, we shall utilize only the records of the 16 days (eight for each season) when it was possible to observe the group continuously, from before daybreak to after sunset. Thus, the observation days began at about $05.45 \mathrm{hr}$ and ended at $19.30 \mathrm{hr}$, with slight differences from one season to another. If the subjects were not observed uninterruptedly during the whole day, the data were not used to assess the activity rhythm.

The group under observation varied from eight to seven individuals during the observation period, with the disappearance of two of their number and one birth. Thus, in the rainy season of 1975, the group consisted of two adult males, four adult females, a juvenile male and a juvenile female. In the dry season, it included two adult males, three adult females, a juvenile female and an infant.

Since the chosen group frequented a line of trees of the outer forest, a hide could be set up for observation at approximately $30 \mathrm{~m}$ from the place most frequented by the animals. If the animals moved to trees farther off, the observer followed them at a distance, hiding himself behind trees and bushes.

When observing this group, the observers always avoided making sudden movements and always wore the same colour clothes. Observations were recorded in a low voice with a smallsized Phillips 0095 tape recorder. The 5 -min periods were controlled with a wrist watch with a minute hand, and the howlers were observed with the help of Leitz $10 \times 40$ binoculars.

The daily rhythm of howling was also recorded, the data being based on all "choruses of howls" heard at any time of day from a specific point. In this way the observer, in the hiding place used for observing the chosen group, recorded the time of commencement and ending of each chorus of howls heard, from wherever it originated. We estimated that a radius of $1 \mathrm{~km}$ was covered, and the data were collected on the same 16 days of complete observations. The 
Table 2. Proportion of total observation time spent on four activities.

\begin{tabular}{lll}
\hline Activity & Dry season $(\%)$ & Rainy season $(\%)$ \\
\hline Sleeping & 37.9 & 43.2 \\
Snoozing & 24.0 & 18.2 \\
Feeding & 19.8 & 23.8 \\
Locomotion & 18.4 & 14.8 \\
\hline
\end{tabular}

same procedure was followed for eight consecutive days, at the beginning of the dry season, in a zone of gallery forest, $20 \mathrm{~km}$ away, where the observer also recorded each chorus of howls heard at any time of the day.

LOCOMOTION

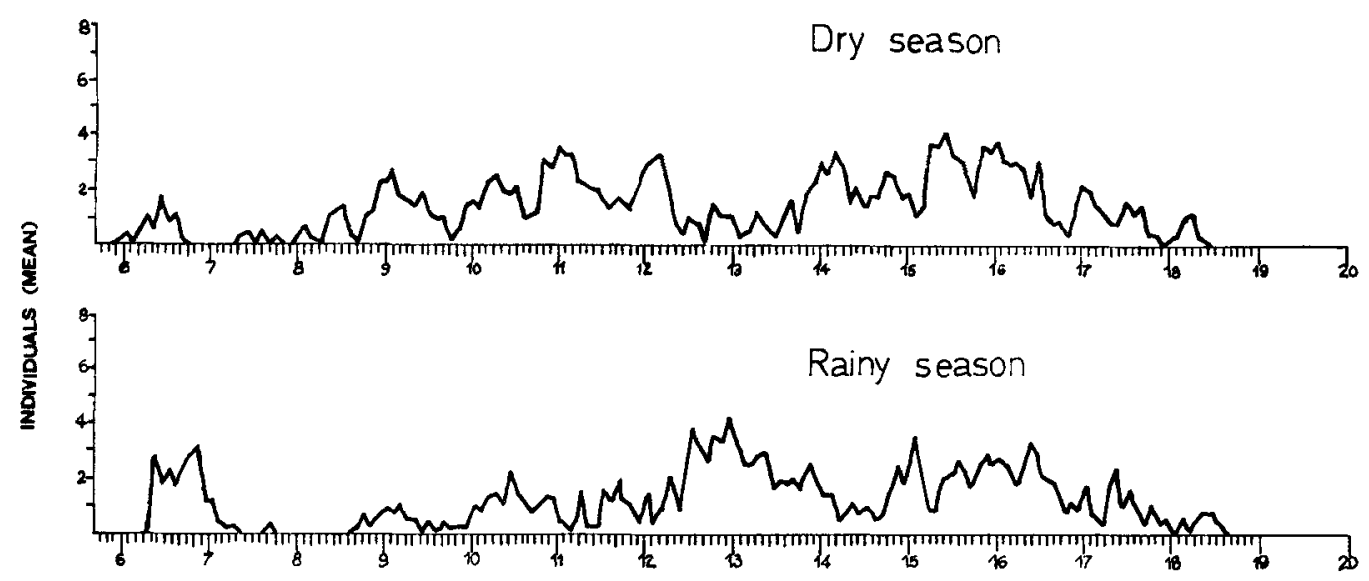

TIME OF DAY

FEEDING
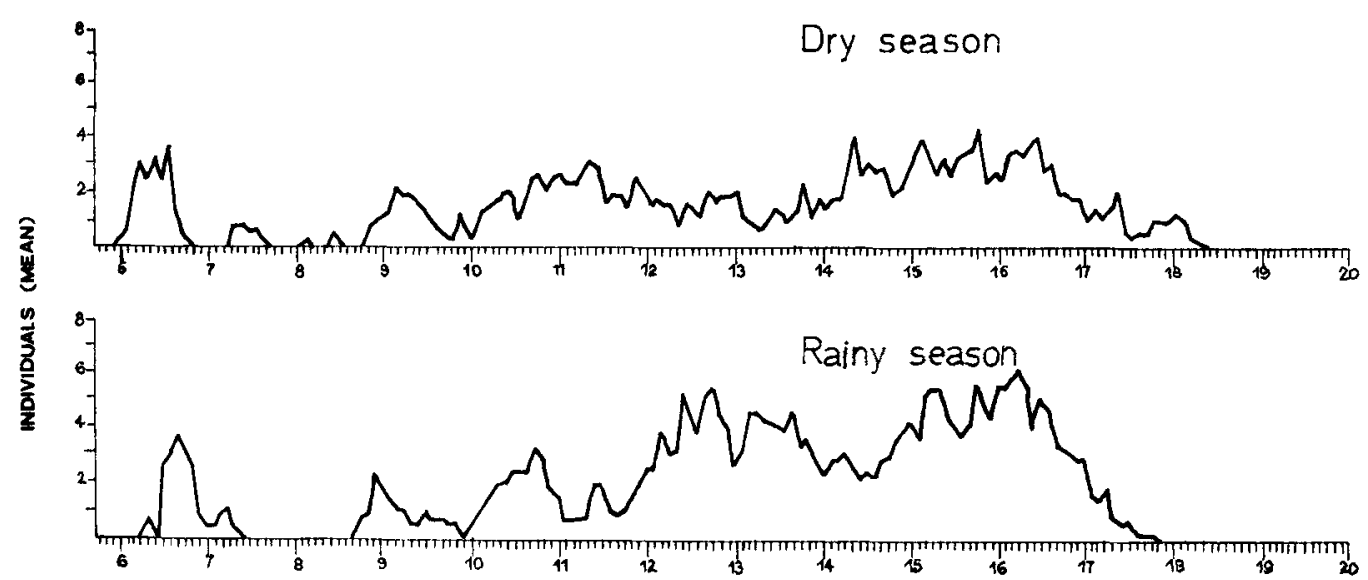

TIME OF DAY

Fig. 5. Activity rhythm for locomotion and feeding in the dry and rainy seasons. 


\section{Time Distribution of Activities}

The distribution of total observation times among the four above mentioned activities at both seasons of the year is summarized in Table 2. It can be seen that the howlers spent a somewhat longer time sleeping and a shorter time snoozing in the rainy season, as compared to the dry season, the differences being less for locomotion and feeding at both seasons. Thus, considering the information for both seasons as a whole, it can be said that almost half of the time was spent sleeping, while feeding and snoozing each took about a quarter of the total time, and locomotion employed only a sixth.
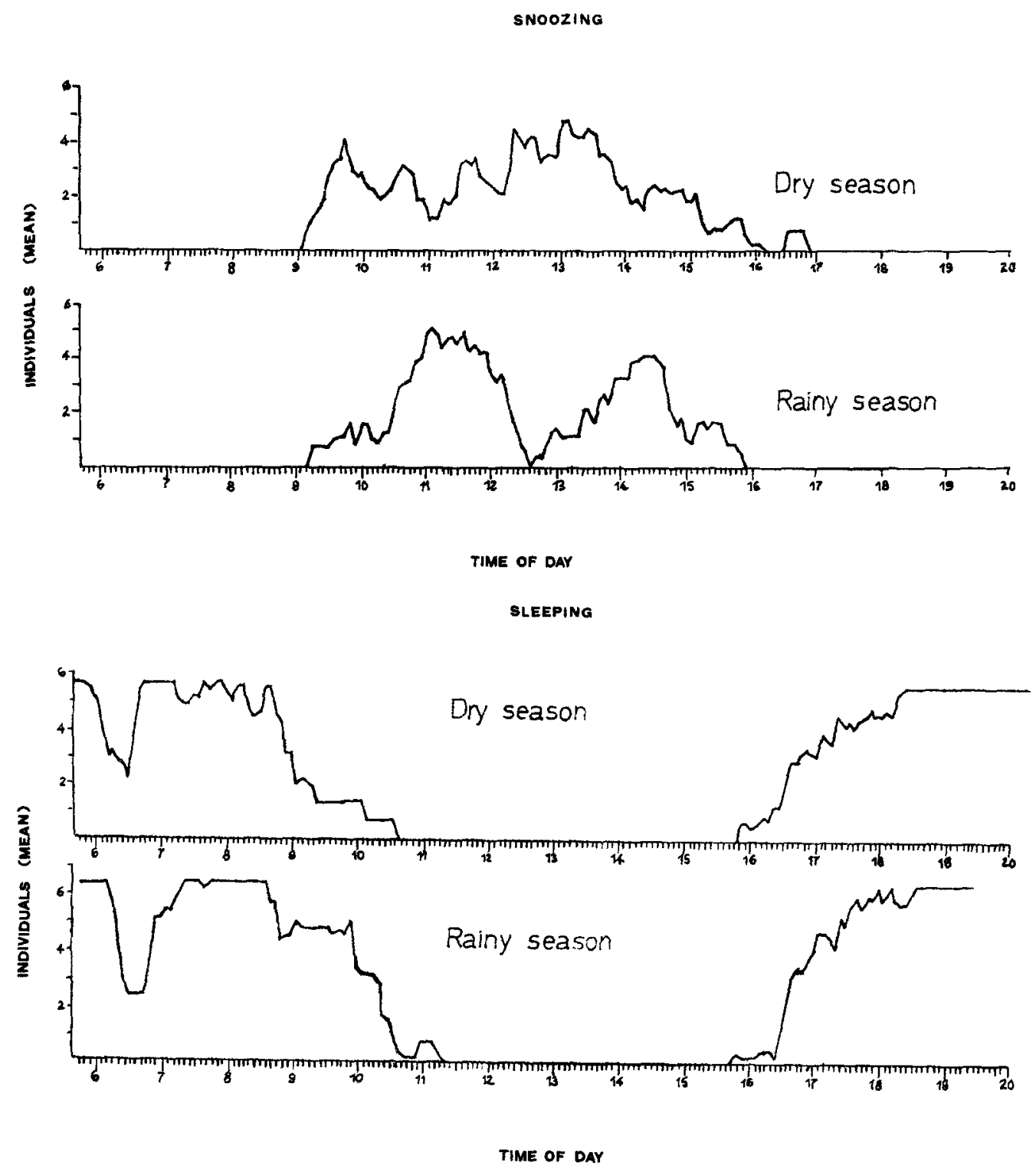

Fig. 6. Activity rhythm for sleeping and snoozing in the dry and rainy seasons. 


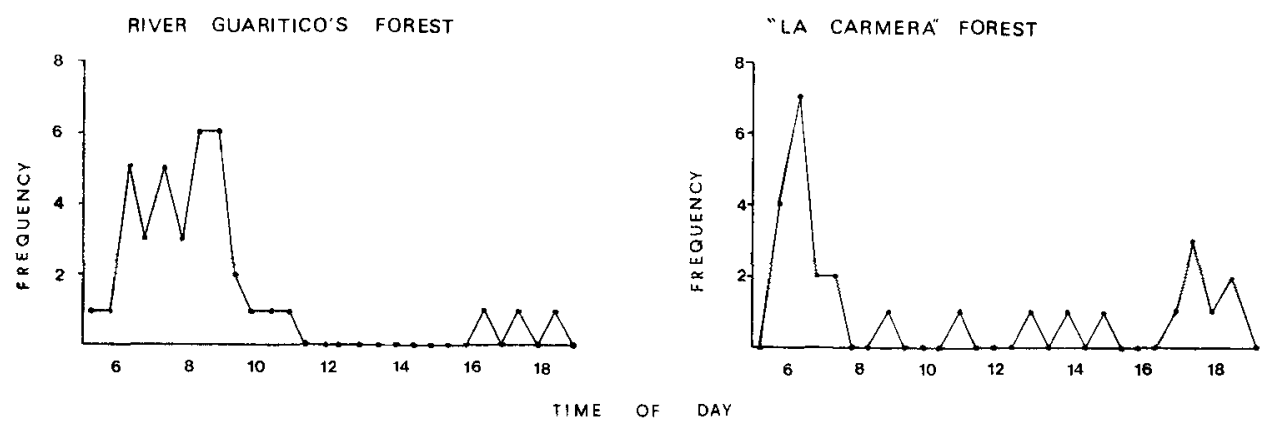

Fig. 7. Frequency of choruses of howls within the day in two forests of the study area.

\section{Daily and SEasonal Rhythms}

The results of the activity rhythm of the chosen group for the above-mentioned activities are presented in Figures 5 to 7 , the criterion for intensity being the number of individuals performing each activity at the end of each 5-min period. Comparisons between the distributions for both seasons did not show any statistically significant differences (Wilcoxon $U$ test).

Locomotion (Fig. 5) begins at daybreak, although after approximately half an hour (longer in the rainy season) and without moving too far from the sleeping site, the howlers go back to sleep in a group. After 40-90 min of sleep (longer in the rainy season), they again move.

From then on, the group keeps moving, showing two peaks of activity (many animals moving) after and before siesta time. At about $16.30 \mathrm{hr}$, the howlers start withdrawing towards the sleeping site, ending locomotion completely at around $18.30 \mathrm{hr}$.

The timing of feeding (Fig. 5) coincides very much with the previously described scheme for locomotion. Thus, for both activities we observed a sharp increase in the early morning, followed by a decrease and then continuous feeding and locomotion during practically the whole day, with a decrease during the siesta period.

As for sleeping (Fig. 6), after waking at daybreak, the howlers sleep again at around 06.45 $\mathrm{hr}$, until approximately $08.45 \mathrm{hr}$. From then on, they move until about $16.15 \mathrm{hr}$, when they return to the sleeping site, although not all animals are asleep until approximately $18.00 \mathrm{hr}$.

Concerning snoozing (Fig. 6), there are two clear siesta periods in the middle of the day (maxima at $13.30 \mathrm{hr}$ and $14.30 \mathrm{hr}$ ) in the rainy season, and only one (maximum at $13.30 \mathrm{hr}$ ) in the dry season.

Finally, as regards the temporal distribution of the choruses of howls (Fig. 7), there is an important peak which begins when the animals wake up and lasts until $09.00 \mathrm{hr}$. They may or may not howl during the day (though very little in any case), but the sounds are heard again towards late afternoon, between 16.00 and $18.30 \mathrm{hr}$.

\section{USE OF SPACE}

\section{LOCATION OF GROUPS}

As a first approach to the study of the use of space in the howlers, we concentrated on the most frequent locations of the groups in the most explored wood ("La Carmera" forest). Figure 8 shows the areas most used by each group, as well as the sites with accumulations of excrement on the ground and those where the choruses of howls took place. 


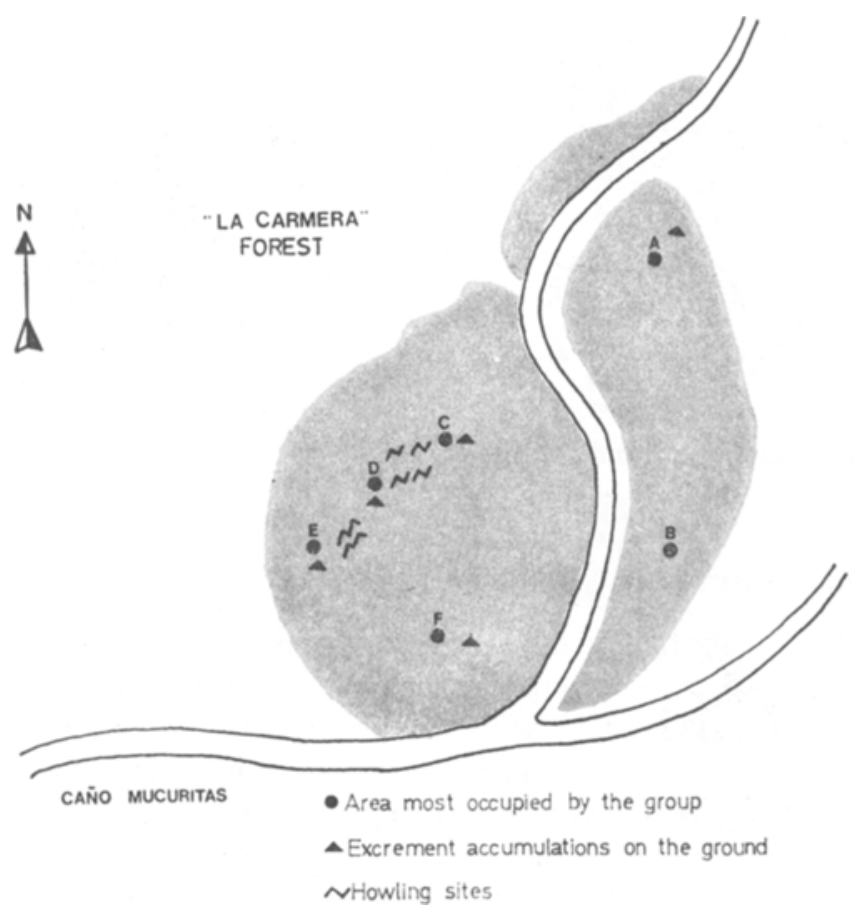

Fig. 8 Most frequent locations of the groups living in "La Carmera" forest. Sites of howling and excrement accumulation are also indicated.

It is noteworthy that certain groups were found in specific areas, and those areas frequented by the different groups were distributed relatively uniformly throughout La Carmera wood (Fig. 8 \& Table 3 ).

In three of the groups (A, C and D), we examined in more detail the specific area most used. This contained trees in two vertical strata: a lower continuous one and a higher stratum of trees 15 to $20 \mathrm{~m}$ in height. The three groups withdrew to sleep in the later evening, each to a specific site, which was also utilized for protection in the event of danger.

In the case of groups $C$ and $D$, whose sleeping sites were very near to each other, the groups were observed directing howling choruses at each other when they withdrew to sleep. Under these circumstances, and within sight of each other, they all came to face their opposite group and, shaking the branches and making short running movements, they howled in chorus in their opposite group's direction.

Table 3. Size and composition of the groups living in La Carmera forest.

\begin{tabular}{clllll}
\hline Group & Adult male & Adult female & Juvenile & Infant & Total \\
\hline A & 2 & 3 & - & 1 & 6 \\
B & 1 & 2 & 1 & 1 & 5 \\
C & 2 & 3 & 3 & 1 & 9 \\
D & 3 & 4 & 2 & 2 & 11 \\
E & 1 & 3 & 1 & 2 & 7 \\
F & Unknown & & & & \\
\hline
\end{tabular}



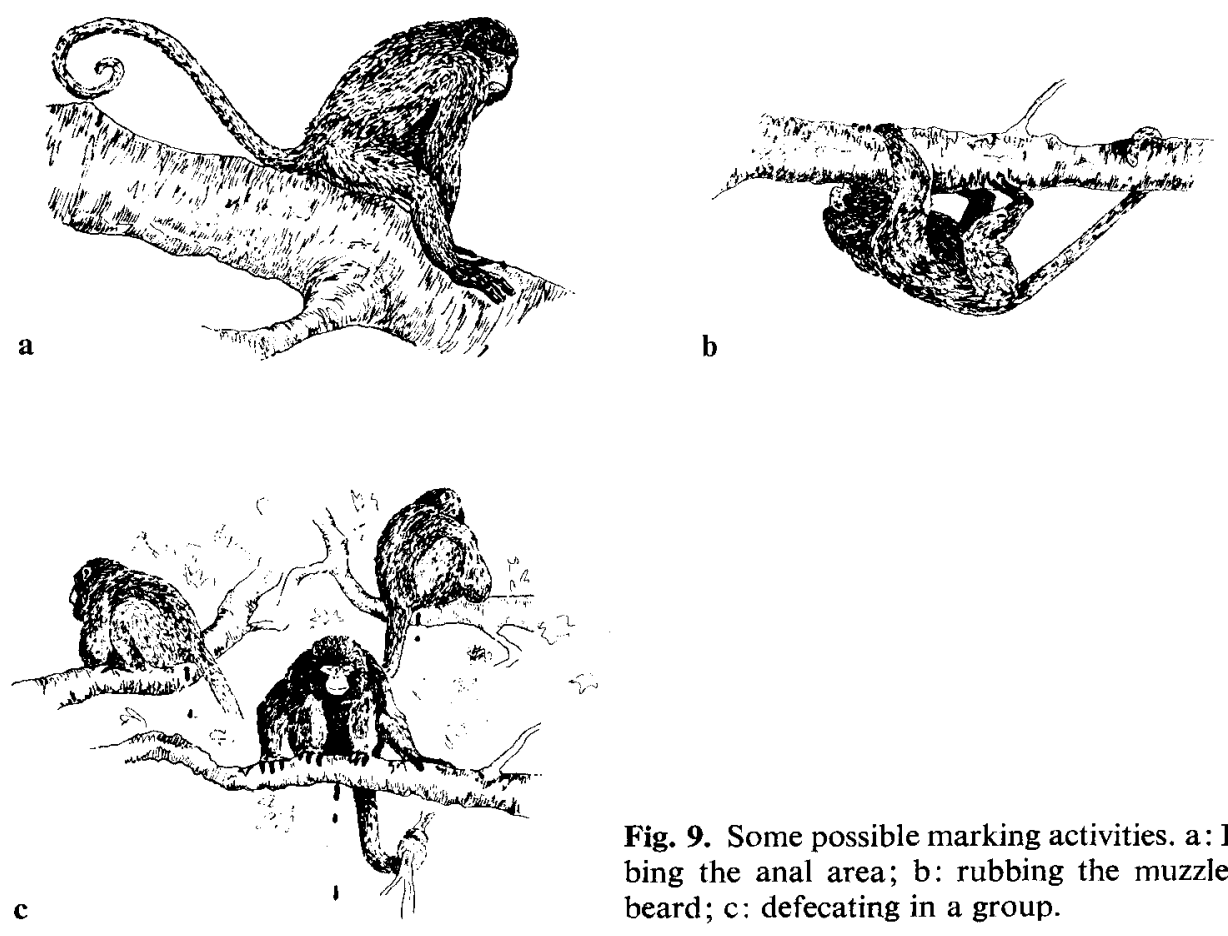

Fig. 9. Some possible marking activities. a: Rubbing the anal area; $b$ : rubbing the muzzle and beard; $c$ : defecating in a group.

Although the use of the chorus of howls as a form of intergroup aggression is not too well known in the different species of howlers, we were able to confirm another kind of behaviour in our subjects which denoted occupation of the sleeping site. This was defecation and subsequent accumulation of the excrement in fecal piles of approximately $1 \mathrm{~m}$ in diameter and of various heights (average $10 \mathrm{~cm}$ ) on the forest floor.

Thus, when the animals first left the sleeping site, between 09.00 and $10.00 \mathrm{hr}$, usually when the individuals of the group passed a certain point in the branches, they would defecate, and on three occasions it was even observed in one group that every member defecated at the same time over that spot. As a result of each group having a particular defecation spot, at a height of between 10 and $15 \mathrm{~m}$, the feces accumulated at certain definite points on the ground. After defecating, the howlers sometimes rubbed their anus on the branches, which then took on a characteristic odour, this perhaps becoming a means of marking (Fig. 9).

Another possible marking activity, performed mainly by adult males, was rubbing of the muzzle and beard on definite points on branches, which the animals licked while secreting abundant saliva (Fig. 9).

\section{VerTical Use of SPACE}

Considering that the animals actually use the space, not just restrict themselves to being within it, we approached the problem by not merely recording the animals' presence but also by taking note of the activities that they were carrying out. The four most frequent uses of the environment in the study group (sleeping, snoozing, locomotion and feeding) were again 
Table 4. Percentage of time spent performing feeding, locomotion, snoozing and sleeping in the tree strata considered.

\begin{tabular}{lcccc}
\hline Tree stratum & Feeding & Locomotion & Snoozing & Sleeping \\
\hline Tops of highest trees (more than $12 \mathrm{~m}$ ) & 1.1 & 5.3 & 7.8 & 97.5 \\
Trees of medium height (up to about & & & 79.1 & 2.5 \\
$\quad 12 \mathrm{~m}$ ) & 49.8 & 66.1 & 13.1 & 0 \\
Low trees (up to 6 m) & 35.7 & 14.9 & 0 & 0 \\
$\begin{array}{l}\text { Herbaceous and brushwood stratum } \\
\quad \text { (about 0-3 m) }\end{array}$ & 13.4 & 13.7 & 0 & \\
\hline
\end{tabular}

considered, and this approach could be extended to an exhaustive analysis of the use of the ethogram in space.

The group under study (the same as that in the activity rhythm section) was suitable in this aspect since most of its time was spent in a narrow border of trees, and so, with only height and length dimensions, the problem could be examined readily. We obtained a detailed profile of the line of trees used, by means of photography and actual measurements. At the end of each 5 min-period, in both seasons of the year, we noted the location of the individuals of the group in the vertical strata of each particular tree as well as the numbers of individuals involved in different activities (sleeping, snoozing, locomotion and feeding).

In this line of trees, the following four vertical strata were distinguished: (1) a herbaceous and brushwood stratum (about 0-3 m); (2) low trees (up to $6 \mathrm{~m}$ ); (3) trees of medium height (up to about $12 \mathrm{~m}$ ); and (4) the tops of the highest trees (more than $12 \mathrm{~m}$ ).

Regarding the sleeping pattern, as indicated in Table 4, the howlers slept preferentially in the highest stratum (4). It is interesting to note also that the activity of fleeing from danger was directed precisely towards these sleeping sites. For this reason, we name them "nightrefuge" sites.

As regards the pattern for snoozing, as shown in Table 4, the main location was immediately below the sleeping sites, which were apparently taken as a reference.

As for locomotion, the third, continuous stratum (3) was the most used, as a continuous corridor. It was also utilized very much for feeding and for gaining access to the two lower strata ( 1 and 2 ) which were also used strongly for feeding.

Table 5. Percentage of time spent performing feeding, locomotion, snoozing and sleeping in the tree strata considered at both seasons of the year.

\begin{tabular}{|c|c|c|c|c|c|c|c|c|}
\hline \multirow[b]{2}{*}{ Tree stratum } & \multicolumn{4}{|c|}{ Rainy season } & \multicolumn{4}{|c|}{ Dry season } \\
\hline & Feeding & $\begin{array}{l}\text { Locomo- } \\
\text { tion }\end{array}$ & Snoozing & Sleeping & Feeding & $\begin{array}{l}\text { Locomo- } \\
\text { tion }\end{array}$ & Snoozing & Sleeping \\
\hline $\begin{array}{l}\text { Tops of highest } \\
\text { trees (more than } \\
12 \mathrm{~m} \text { ) }\end{array}$ & 1.3 & 5.3 & 16.6 & 100 & 0.8 & 5.3 & 4.0 & 93.1 \\
\hline $\begin{array}{l}\text { Trees of medium } \\
\text { height (up to } \\
\text { about } 12 \mathrm{~m} \text { ) }\end{array}$ & 56.2 & 74.6 & 67.5 & 0 & 43.6 & 61.2 & 84.0 & 6.9 \\
\hline $\begin{array}{l}\text { Low trees (up to } \\
6 \mathrm{~m} \text { ) } \\
\text { Herbaceous and } \\
\text { brushwood stratum } \\
\text { (about } 0-3 \mathrm{~m} \text { ) }\end{array}$ & 31.8 & 15.3 & 15.9 & 0 & 39.4 & 14.6 & 12.0 & 0 \\
\hline
\end{tabular}




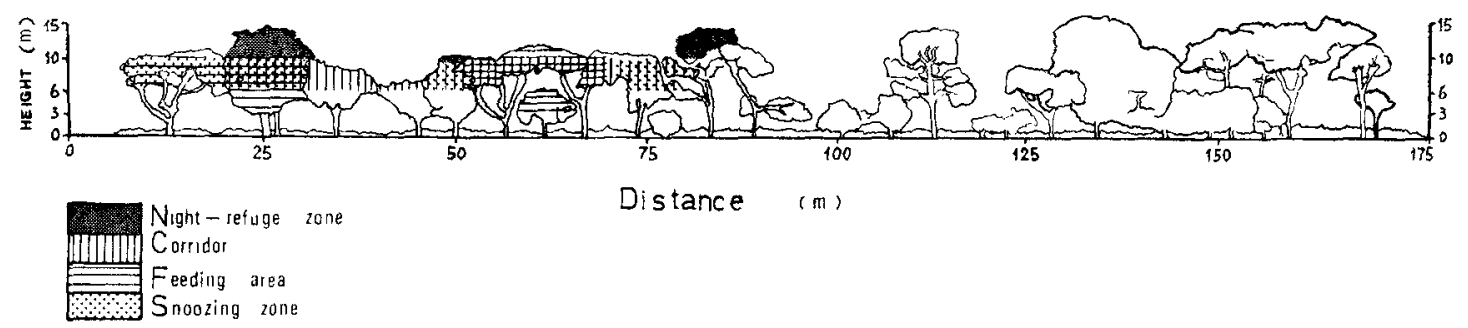

Fig. 10. Summary of the spatial distribution of the different activities of the red howlers.

Comparisons of the patterns of the various activities for the two seasons of the year, revealed no great differences on the whole (Table 5). Nevertheless, the somewhat greater use by the howlers during the dry season of the medium height stratum for sleeping and snoozing and the ground for locomotion, may be of importance.

In summary, as shown schematically in Figure 10, application of our proposed method resulted in a detailed understanding of the use of space by our howlers being gained.

\section{DISCUSSION AND CONCLUSIONS}

The average group size of approximately $6 \pm 2$ individuals found in our study area fits within the normal limits of variation for the species (NEVILLE, 1972; IZAWA, 1976; KLEIN \& KLEIN, 1976). In fact, the typical group size does not appear to differ much from that found for $A$. caraya in Argentina (POPE, 1966), both species differing from the large groups which some populations of $A$. villosa tend towards (CARPENTER, 1934; FreEsE, 1975; CoelHo et al. 1976).

In our population, there was a small and consistent decrease in group size during the rainy season (from an average of 7.3 to 5.3). As regard the composition, our howlers presented a higher proportion of females than males in the groups, these two classes exceeding the numbers of infants and juveniles. Thus, a typical group would show an average of from two to three adult females, one to two adult males, one juvenile and one infant.

It should be noted that juveniles vary more in number as group members than any other class, their decrease at the end of the dry season coinciding with an increase in the number of females at this time. This is probably related to movements towards the group's centre or periphery and could be connected with a peak in sexual activities at this time of the year (Braza, Alvarez \& Azcarate, in press).

For the small groups of $A$. seniculus, the one to two adult males are apparently indispensable, in this respect differing from the situation found in $A$. villosa where the variation in group size appears to be a consequence of the greater mobility of the adult males (CAR PENTER, 1934).

Concerning the time distribution of activities, if the time used for snoozing is combined with that for sleeping, the total time is almost identical in both seasons. It is possible that, perhaps faced with a constant physiological need for sleep, the distribution throughout the day shows some seasonal variation and more siestas are taken during the heat of the day in the dry season, when the animals wake up sooner in the morning.

As a whole, the time spent by our subjects on resting, feeding and walking fell within the limits known for $A$. villosa in Barro Colorado (Altmann, 1959; Mittermeier, 1973). 
Considering the daily rhythm of activities, and comparing our results with those of ALTMANN (1959) for A. villosa in Barro Colorado, our howlers distribute their feeding more throughout the day, although both populations appear to coincide in performing a small amount of feeding in the early morning and a more gradual increase at the end of the day. The pattern for sleeping and locomotion is almost exactly the same in both species.

The howlers' preference for particular areas and their relatively uniform distribution in space seems to be maintained by the emission of choruses of howls, by fecal piles on the forest floor just below the night-refuge zones, and by the marking of certain branches. The function of these activities could be either intertroop territorial defense or just a way of ensuring own range recognition.

As regards the vertical use of space in performing the various activities, we conclude that this is well adapted to the structure of the habitat, being controlled mainly by the howlers' quadrupedal locomotion and the necessity for protection against predators. The middle continuous tree stratum is utilized as a walking corridor, which connects with the night-refuge sites high up in the tallest trees, below which the snoozing or siesta zones are situated. The walking corridor also connects the more variable feeding zones.

Acknowledgements. We would like to express our thanks to Ms. Rosalía Martín, Ms. Annie Simon, Ms. Isabel Bermudo and to Ms. Carolina Carazo for their invaluable help and to Mr. Joaquín LóPEZ-ROJAS for drawing Figure 9.

\section{REFERENCES}

Altmann, S. A., 1959. Field observations on a howling monkey society. J. Mammal., 40(3): 317-330. Baldwin, J. D. \& J. I. Baldwin, 1972. Population density and use of space in howling monkeys (Alouatta villosa) in southwestern Panama. Primates, 13: 371-379.

Baldwin, L. A., T. L. Patterson \& G. Teleki, 1977. Field research on Callitrichid and Cebid monkeys: An historical, geographical and bibliographical listing. Primates, 18: 485-507.

Bernstein, J., 1964. A field study of the activities of howler monkeys. Anim. Behav., 12: 92-97.

Braza, F., F. Alvarez \& T. Azcarate, in press. Nota sobre la reproducción de Alouatta seniculus. Doñana, Acta Vertebrata.

CARPENTER, C. R., 1934. A field study of the behavior and the social relations of howling monkeys. Comp. Psychol. Monogr., 10(2): 1-168.

Coelho, Jr. A., C. A. Bramblett, L. B. Quick \& S. S. Bramblett, 1976. Resource availability and population density in primates: A sociobioenergetic analysis of the energy budgets of Guatemalan howler and spider monkeys. Primates, 17:63-80.

Freese, C., 1975. Censusing Alouatta palliata, Ateles geoffroyi and Cebus capucinus in the Costa Rican dry forest. In: Neotropical Primates. Field Studies and Conservation, R. W. Thorington \& P. G. Heltne (eds.), National Academy of Science, Washington, D.C., pp. 4-9.

IZAWA, K., 1975. Foods and feeding behavior of monkeys in the upper Amazon basin. Primates, 16: 295-316.

- 1976. Group sizes and compositions of monkeys in the upper Amazon basin. Primates, 17: 367-398.

KLEIN, L. L. \& D. J. Klein, 1976. Neotropical primates: Aspects of habitat usage, population density and regional distribution in la Macarena, Colombia. In: Neotropical Primates. Field Studies and Conservation, R. W. Thorington \& P. G. Heltne (eds.), National Academy of Science, Washington, D.C., pp. 70-78.

Mittermeier, R. A., 1973. Group activity and population dynamics of howler monkeys on Barro Colorado Island. Primates, 14: 1-19.

Neville, M. K., 1972. The population structure of red howler monkeys (Alouatta seniculus) in Trinidad and Venezuela. Folia Primatol., 17: 56-86. 
OJasti, J., 1973. Estudio Biologico del Chigüire o Capibara. Fondo Nac. de Investigaciones Agropecuarias, Caracas.

Pope, B. L., 1966. The population characteristics of howler monkeys (Alouatta caraya) in Northern Argentina. Amer. J. Phys. Anthropol., 24(3): 361-370.

Ramia, M., 1966. Tipos de Sabanas en el Estado de Apure. C.B.R., Caracas.

Richards, P. W., 1964. The Tropical Rain Forest. Cambridge.

-Received March 18, 1980; Accepted April 21, 1981

Authors' Names and Address: F. Braza, F. Alvarez and T. AzCarate, Estación Biológica de Doñana, C.S.I. C., Paraguay Street 1-2, Apartado 1056, Sevilla (12), Spain. 